Result(s)* A total of 38 out of 84 evaluable patients at 6 months included in Paloma trial were above 40yo [mean(SD) age: 47.71(5.56)], of which 30 and 13 were HR HPV and 16-18-31 HPV patients, respectively. At 6 months, normal cytology and concordant colposcopy was observed in $92 \%$, $90 \%$ and $75 \%$ of patients treated with Papilocare ${ }^{\circledR}$ vs $50 \%$, $33 \%$ and $40 \%$ of patients in control group, in the total, HR and $16-18-31$ populations $(p=0.0066 ; p=0.0031 ; p=0.2929$, Fisher test) respectively.

Conclusion* Papilocare ${ }^{\circledR}$ showed a robust and clinically significant efficacy in repairing cervical HPV lesions in women over 40 years, with a statistically significant difference vs control group in the total and HR populations.

\section{TUBECTOMY WITH DELAYED OOPHORECTOMY AS ALTERNATIVE FOR RISK-REDUCING SALPINGO- OOPHORECTOMY IN HIGH-RISK WOMEN TO ASSESS THE SAFETY OF PREVENTION}

${ }^{1} M P$ Steenbeek*, ${ }^{1} \mathrm{M}$ Van Bommel, ${ }^{2} \mathrm{E}$ Swisher, ${ }^{3} \mathrm{~K}$ Lu, ${ }^{4} \mathrm{R}$ Hermens, ${ }^{1} \mathrm{~J}$ De Hullu. ${ }^{1}$ Radboud University Medical Center, Department of Obstetrics and Gynecology, Nijmegen, Netherlands; 'University of Washington-Seattle Cancer Care Alliance, Seattle, USA; ${ }^{3}$ University of Texas M.D. Anderson Cancer Center, Department of Gynecologic Oncology and Reproductive Medicine, Texas, USA; ${ }^{4}$ Radboud University Medical Center, Scientific Institute for Quality of Healthcare, Nijmegen, Netherlands

\subsection{6/ijgc-2021-ESG0.552}

Introduction/Background* Risk-reducing salpingectomy (RRS) with delayed oophorectomy (DO) has gained interest for women at high risk for ovarian cancer in the last years. In the first place because of the increasing number of studies pointing towards the fallopian tube as tissue of origin. In the second place because two studies demonstrated the positive effect on menopause-related quality of life and sexual functioning compared to standard risk reducing salpingo-oophorectomy (RRSO). However, the strategy is not yet proven to be safe. In the current TUBA-WISP II study, we aim to investigate whether RRS with $\mathrm{DO}$ is non-inferior to the current standard RRSO regarding ovarian cancer risk.

Methodology In this international prospective multicenter preference trial, women choose between the novel RRS with DO and the current standard RRSO. RRS can be performed after the completion of child bearing and until the age of 40 (BRCA1), 45 (BRCA2) or 50 (BRIP1, RAD51C and RAD51D pathogenic variant (PV) carriers). Subsequent DO is recommended at a maximum delay of five years beyond the upper limit of the current guideline age for RRSO. The current guideline age, which is also recommended for RRSO within the study, is 35-40 for BRCA1, 40-45 for BRCA2 and 45-50 for BRIP1, RAD51C, and RAD51D PV-carriers. The primary outcome measure is the cumulative ovarian cancer incidence at target age: 46 for BRCA1 and 51 for BRCA2-PV carriers. A total $1500 B R C A 1$ and $1500 B R C A 2-P V$ carriers are needed to prove non-inferiority of RRS with DO compared to RRSO. Kaplan-Meier analysis with Inverse probability weighting will be used to estimate the cumulative incidence at the appropriate target age (46 or 51) per BRCA-type.

Result(s)*

Conclusion* As RRS with DO is proven to be beneficial in regard to menopause-related quality of life and sexual functioning, the current international study is investigating the non-inferiority to RRSO regarding ovarian cancer incidence. Trial registration NCT04294927

\section{REAL-LIFE EFFICACY OF A MULTI-INGREDIENT CORIOLUS VERSICOLOR-BASED VAGINAL GEL IN HIGH- RISK HPV PATIENTS: THE PAPILOBS STUDY FINAL RESULTS}

${ }^{1} Y$ Gaslain, ${ }^{2}$ C Cortés*, ${ }^{3}$ J De Santiago, ${ }^{4} S$ González, ${ }^{5} \mathrm{AE}$ Del Villar, ${ }^{6} \mathrm{C}$ Garcia, ${ }^{2} \mathrm{P}$ Hernández, ${ }^{7} \mathrm{M}$ Agenjo, ${ }^{8} \mathrm{M}$ Gurrea, ${ }^{9} \mathrm{P}$ Sanjuan, ${ }^{1} \mathrm{P}$ Sanmartin. ${ }^{1}$ Procare Health; ${ }^{2}$ Private Practice; ${ }^{3}$ Centro Oncológico MD Anderson; ${ }^{4} \mathrm{HM}$ Gabinete Velázquez; ${ }^{5} \mathrm{Cl}$ línica MilleniumDent; ${ }^{6} \mathrm{HM}$ San Francisco; ${ }^{7}$ Hospital Sanitas La Zarzuela; ${ }^{8}$ Hospital La Fe; ${ }^{9}$ Clínica Ginemed

\subsection{6/ijgc-2021-ESG0.553}

Introduction/Background* The objective was to evaluate the efficacy of Papilocare ${ }^{\circledR}$-a multi-ingredient Coriolus versicolorbased vaginal gel- on repairing high-risk (HR) HPV-dependent low-degree cervical lesions and HR-HPV clearance in real-life practice.

Methodology Observational, multicenter, prospective, onecohort study (PAPILOBS study ClinicalTrial.gov: NCT04199260). Vaccinated or not HPV-positive women aged $>25 y$ with Pap smear (Ps) of ASCUS or LSIL and concordant colposcopy were included during routine clinical visits in Spain. Patients were treated with Papilocare ${ }^{\circledR} 1$ cannula/day for 21 days during first month +1 cannula/alternate days for 5 months. After this 6-month period, patients with altered cytology and/or HPV persistency were treated for a 6-month extension treatment period with the same dosage. Analysis of HR-HPV patients with normal Ps and concordant colposcopy image (primary endpoint) and patients with HR-HPV cleared (totally or partially together with negative Ps and normal colposcopy) at $6 / 12$ months is presented. The study was approved by an IRB and informed consent was signed by patients.

Result(s)* At 6 months, data of 178 and 176 patients for Ps/ colposcopy and HR-HPV presence, respectively, were available. $68 \%$ of patients $(121 / 178)$ had negative Ps and concordant colposcopy. HR-HPV clearance was observed in $57.4 \%$ of patients (101/176). Data of 68 patients included in the 6month extension treatment period for Ps/colposcopy and HRHPV presence were available. At 12 months, 79.4\% (54/68) of patients had negative Ps and concordant colposcopy and HR-HPV clearance was observed in $61.7 \%$ (42/68). Considering all study period, $76.4 \%$ and $70.6 \%$ of patients repaired HR-HPV-dependent cervical lesions and cleared HR-HPV, respectively.

Conclusion* In this real-life study, repairing of HR-HPVdependent low-degree cervical lesions and clearing HR-HPV were achieved after 6-month treatment with Papilocare ${ }^{\circledR}$ (extending it up to 12-months if needed) in 3 out of 4 patients. These findings are consistent with the Paloma Trial's' ones (ClinicalTrials.gov NCT04002154) and other observational studies results.

\section{FEASIBILITY AND THE EFFICACY OF RRSO COMBINED WITH SIMULTANEOUS MASTECTOMY AND BREAST RECONSTRUCTION IN BRCA 1-2 PATIENTS}

${ }^{1} \mathrm{G}$ Bonaldo*, ${ }^{1} \mathrm{M}$ Noventa, ${ }^{1} \mathrm{G}$ Spagnol, ${ }^{1} \mathrm{M}$ Marchetti, ${ }^{1} \mathrm{~S}$ Tosatto, ${ }^{2} \mathrm{~F}$ Bozza, ${ }^{2} \mathrm{~T}$ Saibene, ${ }^{2} \mathrm{~S}$ Michieletto, ${ }^{2} \mathrm{M}$ Toffanin, ${ }^{1} \mathrm{R}$ Tozzi, ${ }^{1} \mathrm{C}$ Saccardi. ${ }^{1} \mathrm{Clinic}$ of Gynecology and Obstetrics, University of Padua, Women and Children's Health, Italy; ${ }^{2}$ Breast Surgery Unit, Veneto Institute of Oncology, Padua

10.1136/ijgc-2021-ESG0.554 